\title{
Routine gastric residual volume measurement and energy target achievement in the PICU: a comparison study
}

\author{
Lyvonne N. Tume ${ }^{1} \cdot$ Anna Bickerdike $^{2} \cdot$ Lynne Latten $^{3} \cdot$ Simon Davies $^{4} \cdot$ \\ Madeleine H. Lefèvre $^{5}$ • Gaëlle W. Nicolas ${ }^{5}$. Frédéric V. Valla ${ }^{6}$
}

Received: 22 April 2017 /Revised: 4 September 2017 / Accepted: 5 September 2017 / Published online: 18 September 2017

(C) The Author(s) 2017. This article is an open access publication

\begin{abstract}
Critically ill children frequently fail to achieve adequate energy intake, and some care practices, such as the measurement of gastric residual volume (GRV), may contribute to this problem. We compared outcomes in two similar European Paediatric Intensive Care Units (PICUs): one which routinely measures GRV (PICU-GRV) to one unit that does not (PICU-noGRV). An observational pilot comparison study was undertaken. Eighty-seven children were included in the study, 42 (PICU-GRV) and 45 (PICU-noGRV). There were no significant differences in the percentage of energy targets achieved in the first 4 days of PICU admission although PICU-noGRV showed more consistent delivery of median (and IQR)
\end{abstract}

Communicated by Mario Bianchetti

Lyvonne N. Tume

Lyvonne.Tume@UWE.ac.uk

Anna Bickerdike

anna.bickerdike@hotmail.com

Lynne Latten

Lynne.latten@alderhey.nhs.uk

Simon Davies

S.davies5@nhs.net

Madeleine H. Lefèvre

madeleine.lefevre33@gmail.com

Gaëlle W. Nicolas

gaelle-nicolas@laposte.net

Frédéric V. Valla

Frederic.valla@chu-lyon.fr energy targets and less under and over feeding for PICU-GRV and PICU-noGRV: day 137 (14-72) vs 44 (0-100), day $297(53-126)$ vs $100(100-100)$, day 384 $(45-112)$ vs $100(100-100)$ and day $4101(63-124)$ vs 100 (100-100). The incidence of vomiting was higher in PICU-GRV. No necrotising enterocolitis was confirmed in either unit, and ventilator-acquired pneumonia rates were not significantly different ( 7.01 vs 125.31 per 1000 ventilator days; $p=0.70$ ) between PICU-GRV and PICUnoGRV units.

Conclusions: The practice of routine gastric residual measurement did not significantly impair energy targets in the first 4 days of PICU admission. However, not measuring GRV did
1 Faculty of Health and Applied Sciences, University of West of England, Glenside Campus, Blackberry Hill, Stapleton, Bristol BS16 1DD, UK

2 School of Medicine, University of Liverpool, MBChB Office, Cedar House, Ashton Street, Liverpool L69 3GE, UK

3 Department of Dietetics, Alder Hey Children's NHS Foundation Trust, Eaton Road, Liverpool L12 2AP, UK

4 Department of Anaesthesia, Royal Oldham Hospital, Rochdale Road, Manchester OL1 2JH, UK

5 University of Lyon Claude Bernard Lyon 1, 43 Boulevard du 11 Novembre 1918, 69100 Lyon-, Villeurbanne, France

6 Pediatric Intensive Care Unit, Hôpital Femme Mère Enfant, Hospices Civils de Lyon, 59 bd Pinel, 69500 Lyon-, Bron, France 
not increase vomiting, ventilator-acquired pneumonia or necrotising enterocolitis, which is the main reason clinicians cite for measuring GRV.

\section{What is known:}

- The practice of routinely measuring gastric residual volume is widespread in critical care units

- This practice is increasingly being questioned in critically ill patients, both as a practice that increases

- The likelihood of delivering inadequate enteral nutrition amounts and as a tool to assess feeding tolerance

What is new:

- Not routinely measuring gastric residual volume did not increase adverse events of ventilator acquired pneumonia, necrotising enterocolitis or vomiting.

- In the first 4 days of PICU stay, energy target achievement was not significantly different, but the rates of under and over feeding were higher in the routine GRV measurement unit.

Keywords Enteral feeding $\cdot$ Paediatric intensive care . Nursing practice $\cdot$ Nutrition $\cdot$ Feeding tolerance

$\begin{array}{ll}\text { Abbreviations } \\ \text { CDC } & \text { Centre for Disease Control } \\ \text { ETT } & \text { Endotracheal tube } \\ \text { EN } & \text { Enteral nutrition } \\ \text { GRV } & \text { Gastric residual volume } \\ \text { IRB } & \text { Institutional Review Board } \\ \text { NEC } & \text { Necrotising enterocolitis } \\ \text { PICU } & \text { Paediatric Intensive Care Unit } \\ \text { PIM score } & \text { Paediatric Index of Mortality } \\ \text { RDA } & \text { Recommended dietary allowance } \\ \text { SPSS } & \text { Statistical Package for the Social Sciences } \\ \text { VAP } & \text { Ventilator-acquired pneumonia } \\ \text { UK } & \text { United Kingdom }\end{array}$

\section{Introduction}

Inadequate delivery of enteral nutrition remains a problem in critically ill children. An international study involving 800 children in 31 PICUs found that only $37 \%$ of children received their prescribed energy intake whilst in intensive care, and it took nearly 12 days for them to achieve even $90 \%$ of their calorie target [23]. A common nursing practice to assess enteral nutrition (EN) 'tolerance' is to measure gastric residual volume (GRV) regularly in critically ill patients, and it is often a factor in the decision to stop or hold enteral nutrition [33, 35]. Indeed, perceived 'high' GRV levels often lead to withholding EN, and such interruptions are a common barrier to delivering EN in PICUs [16]. Despite this, the evidence for GRV to assess feed tolerance is poor, with GRV not correlating consistently to enteral feeding volumes and the measurement itself often being inaccurate $[2,18,20]$. In addition, what volume constitutes an 'acceptable' level of GRV remains unknown. GRV is routinely measured in all UK PICUs [33]. This practice, however, is very variable in terms of frequency, acceptable volumes and actions in response to GRV [33], yet it is not standard practice in $40 \%$ of French PICUs [35]. Thus, we aimed to compare outcomes in a PICU which routinely measures GRV to a PICU that does not.

\section{Methods}

An observational pilot comparison study was undertaken between two paediatric intensive care units. PICU-GRV is a PICU that routinely measured GRV in Liverpool, UK; PICU-noGRV is a unit that does not routinely measure GRV in Lyon, France. The units were comparable by size and volume, but as the PICU-noGRV did not admit cardiac surgical children, these patients were excluded in PICU-GRV. The study objectives were to identify whether routine GRV measurement impacted on energy delivery in mechanically ventilated PICU patients and to identify whether routine GRV measurement impacted on the incidence of complications: vomiting, necrotising enterocolitis (NEC) and ventilatoracquired pneumonia (VAP). The study inclusion criteria were as follows:

- Mechanically ventilated children (0-17 years) admitted onto the PICU with a nasogastric tube or gastrostomy tube in situ

- Invasive ventilation expected to last for more than $72 \mathrm{~h}$

The exclusion criteria were as follows:

- Post-operative cardiac surgical children

- Pre-term infants < 37 weeks' gestation (but history of prematurity was not an exclusion criteria)

- Children $>17$ years of age

- Children who had contraindications for enteral feeding according to local guidelines (see Table 1)

- Children who received post-pyloric feeding

Data was collected in 2016-2017 prospectively in PICUGRV and retrospectively in PICU-noGRV at two time points within a 12-month period. The settings and standard practices (that may impact on nutrition and enteral feeding) are compared between the two centres in Table 1. Both units used predictive equations (Schofield equation) to set energy targets in ventilated children, as neither centre used indirect calorimetry. PICUnoGRV increased energy targets for children under the age of 4 months, following the equation (Schofield + RDA)/2. 
Table 1 Comparison of standard practices in study units that may have an impact on feeding tolerance and gastric clearance

\begin{tabular}{|c|c|c|}
\hline Variable/practice & PICU 1 (routine GRV) & PICU 2 (no routine GRV) \\
\hline Unit Size & $\begin{array}{l}24 \text { PICU beds } \\
\text { Admits } 0-17 \text { years }\end{array}$ & $\begin{array}{l}23 \text { PICU and HDU beds } \\
\text { Admits } 0-17 \text { years }\end{array}$ \\
\hline $\mathrm{RN}$ : patient ratio & $1: 1$ & $1: 2$ \\
\hline $\begin{array}{l}\text { Nursing staff with } \\
\text { specialist PIC } \\
\text { qualification }\end{array}$ & $52 \%$ & $5 \%$ \\
\hline Written feeding policy & Yes & Yes \\
\hline Dedicated dietetic support & Yes & Yes \\
\hline Energy target estimation & Schofield equation (adjusted age, sex weight) & $\begin{array}{l}\text { Schofield equation-adjusted age, sex, height, weight) or } \\
\text { (Schofield }+ \text { RDA) } / 2 \text { in infants }<4 \text { months }\end{array}$ \\
\hline $\begin{array}{l}\text { Energy goals } \\
\text { (sedated ventilated } \\
\quad \text { children) }\end{array}$ & $\begin{array}{l}\text { Aims to achieve target predicted energy } \\
\text { requirements by day } 2 \text { or } 3\end{array}$ & Aims to achieve target predicted energy requirements by day 2 or 4 \\
\hline GRV measured & $\begin{array}{l}\text { Yes, every } 4-5 \mathrm{~h} \\
\text { Feeds withheld if }>5 \mathrm{mls} / \mathrm{kg} \text { or maximum } \\
\quad 300 \mathrm{ml}\end{array}$ & No \\
\hline Feeding method used & $\begin{array}{l}\text { Bolus feeding in infants q } 2-3 \text { hourly and } \\
\text { continuous feeds ( } 4 \mathrm{~h} \text { on } 1 \mathrm{~h} \text { off) in older } \\
\text { children, but method is } \mathrm{RN} \text { decision }\end{array}$ & $\begin{array}{l}\text { All continuous over } 24 \mathrm{~h} \text { continuous infusion rate calculated on a } 23 \mathrm{~h} \\
\text { basis }(\mathrm{mL} / \mathrm{h}=\text { daily prescribed volume } / 23) \text { to compensate } \\
\text { involuntary delay }\end{array}$ \\
\hline Target feed start time & Within $6 \mathrm{~h}$ of admission & Within $24 \mathrm{~h}$ of admission \\
\hline Feed advancement rate & $\begin{array}{l}\text { Dependant on feed tolerance based } \\
\text { on the GRV measurements above }\end{array}$ & Once a day with the aim to meet energy targets within $48-96 \mathrm{~h}$ \\
\hline Jejunal tubes & $\begin{array}{l}\text { Not as a first line, except severe burns, } \\
\text { but placed if NG feeds not tolerated }\end{array}$ & $\begin{array}{l}\text { Not in the first place; if high risk patients (brain injury) or feeding } \\
\text { intolerance }\end{array}$ \\
\hline $\begin{array}{l}\text { Polymeric/semi-elemental } \\
\text { feeds }\end{array}$ & $\begin{array}{l}\text { Polymeric unless history of short } \\
\text { gut/liver dysfunction }\end{array}$ & Polymeric unless child on elemental feeds prior to admission \\
\hline $\begin{array}{l}\text { Isocaloric/hyper-caloric } \\
\text { feeds }\end{array}$ & $\begin{array}{l}\text { Isocaloric first line then adjusted to } \\
\text { meet requirements }\end{array}$ & Isocaloric ( $85 \%$ patients) \\
\hline Fibres/no fibres in EN & $\begin{array}{l}\text { Fibre feeds except if history of GI pathology } \\
\text { (short gut, etc) }\end{array}$ & Fibres added \\
\hline $\begin{array}{l}\text { Use of prokinetics, } \\
\text { laxatives }\end{array}$ & $\begin{array}{l}\text { Not routine, only in traumatic brain injury } \\
\text { or if feeding problems }\end{array}$ & Not routine, only in acute neurological disease or if feeding problems \\
\hline $\begin{array}{l}\text { Guidance on } \\
\text { withholding EN }\end{array}$ & $\begin{array}{l}\text { Bowel obstruction, active gut haemorrhage, } \\
\text { non-intubated patients with acute altered } \\
\text { consciousness } \\
\text { Not restricted if on vasoactive drugs or, } \\
\text { only if serum lactate }>2 \mathrm{mmol} / \mathrm{l}\end{array}$ & $\begin{array}{l}\text { Bowel obstruction, active gut haemorrhage, non-intubated patients with } \\
\text { acute altered consciousness, increasing doses of vasoactive drugs but } \\
\text { physician-dependent }\end{array}$ \\
\hline Guidance on stopping EN & $\begin{array}{l}\text { Vomiting, abdominal distension, pain } \\
\text { If lactate }>2 \mathrm{mmol} / \mathrm{l} \text {, large GRV } \\
>5 \mathrm{ml} / \mathrm{kg} \text { or } 300 \mathrm{ml} \\
6 \mathrm{~h} \text { prior to extubation } \\
\text { For transport: depends on procedure }\end{array}$ & $\begin{array}{l}\text { Vomiting, abdominal distension, pain } \\
4 \mathrm{~h} \text { prior to extubation } \\
\text { For transport: immediately prior }\end{array}$ \\
\hline Use of cuffed ETTs & $75 \%$ & $95 \%$ \\
\hline $\begin{array}{l}\text { Usual sedation and } \\
\text { analgesia for } \\
>1 \text { day ventilation }\end{array}$ & Morphine or fentanyl and midazolam & Sufentanyl and midazolam \pm ketamine \\
\hline Sedation assessment score & COMFORT-B & COMFORT-B \\
\hline VAP bundle & $\begin{array}{l}\text { Yes, with head up and regular oral care } \\
\text { and closed suction }\end{array}$ & No but all nursed head up 30-45 degrees + regular oral care \\
\hline $\begin{array}{l}\text { Use of neuromuscular } \\
\text { blocking agents }\end{array}$ & $\begin{array}{l}30 \% \text { patients (mainly brain injury, unstable } \\
\text { airways, difficult ventilation ARDS) }\end{array}$ & $7 \%$ of all patients (mainly ARDS, brain injury, airway surgery) \\
\hline VAP diagnostic criteria & CDC 2009 and antibiotics started & CDC 2009 and antibiotics started \\
\hline
\end{tabular}

Shaded rows indicate major differences between PICU-GRV and PICU noGRV

$R N$ registered nurse, $P I C$ Paediatric Intensive Care, GRV gastric residual volume, $H D U$ high dependency unit, $E N$ enteral nutrition, ETTs endotracheal tubes, COMFORT-B a sedation scoring tool, VAP ventilator acquired pneumonia, $A R D S$ acute respiratory distress syndrome, $R D A$ recommended dietary allowance, $C D C$ Centre for Disease Control, $N G$ nasogastric 
The primary outcome used in this study was the percentage of target energy requirements achieved per day of the child's PICU stay. Secondary outcomes were incidence of vomiting, NEC (in infants) and VAP. VAP was defined consistently using the 2009 CDC criteria. The diagnosis of NEC was confirmed using Bell's criteria and suspected NEC defined if active intervention was taken (instituting fasting and the commencement of triple antibiotics). Vomiting was defined pragmatically, as that reported and documented by the bedside nurse and any incidence of these per $24 \mathrm{~h}$ was considered as a positive event.

\section{Data analysis}

Data collected was entered into a Microsoft Excel database. Descriptive statistics were undertaken first. Normally distributed data is presented as mean (SD) and non-normally distributed data as median and IQR. The data was then imported into IBM SPSS version 22 for further inferential analysis. Inferential analysis undertaken compared the two groups. Independent $t$ test was used if the data was normally distributed and non-parametric tests, Mann-Whitney and Chi-square used if it was not. A $p$ value $<0.05$ was considered significant and two-tailed tests were used. The UK study was registered as service evaluation with the NHS Trust (reference 5194) and in France, the centre received IRB approval (Reference No. 00009118, Comité de protection des personnes 89 Lyon sudest 2); in both instances, a waiver of consent was granted as no identifiable patient data was collected.

\section{Results}

Eighty-seven children who met the study inclusion criteria were included in the study over two time periods in a 12month period: 42 in PICU-GRV and 45 in PICU NoGRV. There was no significant difference in age, weight or sex between the two groups. The median age was 5.3 months (PICU-GRV) vs 9.7 months (PICU-noGRV); the median weight was $5.4 \mathrm{~kg}$ (PICU-GRV) vs $9.8 \mathrm{~kg}$ (PICU-noGRV) and $60 \%$ children were male (Table 2). The majority of admitted children had a medical diagnosis, mostly respiratory or neurological failure (Table 2). Children in PICU-noGRV were significantly sicker at admission $(p<0.001)$ and had significantly longer length of ventilation $(p=<0.001)$ and length of PICU stay ( $p=<0.001)$. Between PICU-GRV and PICUnoGRV, a comparison of standard practices that may have an impact on feeding tolerance and gastric clearance was broadly similar. (Table 1). The main differences were that PICU-GRV initiated enteral feeding significantly earlier than did PICU noGRV (mean 7.8 (7.4) versus 21.5 h $(18.3))(p=<0.001)$, and PICU-noGRV fed all (100\%) children continuously, compared to $41 \%$ in PICU-GRV $(p=<0.001)$. There were no significant differences in the median percentage of energy targets achieved in the first 4 days of PICU admission; however, PICU-noGRV showed more consistent (with less variance around $100 \%$ of the predicted energy targets achieved) and less under and over feeding (Table 3). The incidence of vomiting (between day 1 to 4 ) was higher in the PICU-GRV but was not statistically significant $(p=0.339)$. No NEC was confirmed in either centre and VAP rates were similar 7.01 per 1000 ventilator days (2/42) in PICU-GRV and 5.31 per 1000 ventilator days $(3 / 45)$ in PICU-noGRV $(p=0.70)$, despite the significantly longer length of ventilation in PICU-noGRV (Table 4).

In PICU-GRV, enteral feeding was withheld in all children for a median range of between $8.8-10.5 \mathrm{~h}$ a day in the first 4 days (Table 3). PICU-noGRV rarely withheld enteral feeding. In PICU-GRV, GRV was measured from 2 to 15 times in a 24-h period. The mean volume of aspirate obtained per patient was $1.2 \mathrm{mls} / \mathrm{kg}$ (median $0.96 \mathrm{mls} / \mathrm{kg}$; range $0.03-3.3 \mathrm{mls} / \mathrm{kg}$ ). Of the aspirates where fluid was aspirated, $77 \%$ of these were returned to the child and $23 \%$ were discarded, with the reason for this unclear.

\section{Discussion}

This is the first study to our knowledge to attempt to describe the impact of routine GRV monitoring on critically ill children's clinical outcomes. In two similar groups of patients, recruited in units with similar standards of nutritional care except for the measurement of GRV, we found that the routine measurement of GRV did not impair the achievement of energy goals in the first 4 days of PICU admission. More importantly, we showed that the practice was safe, with no difference in adverse events of VAP or NEC but with the incidence of vomiting higher in PICU-GRV. GRV measurement is based on many assumptions held by the healthcare team: the belief that the measurement is accurate, it represents gastric contents and helps to distinguish delayed gastric emptying; that high GRV only occurs if gastric emptying is delayed and indicates retention of enteral feed; the belief that increased volume of enteral feed in the stomach leads to vomiting and aspiration and that this aspiration leads to pneumonia (VAP) [18]. Indeed, as GRV is composed of both enteral feed and gastric secretions, it does not provide an accurate indicator of feed 'tolerance'. No studies have ever demonstrated that measuring GRV reduces the risk of VAP, and no relationship has yet been established between higher gastric volumes and vomiting and pulmonary aspiration. Indeed, the measurement of GRV has been shown to frequently be inaccurate due to tube position in the stomach, syringe size, nasogastric tube diameter, feeding method and aspiration technique $[2,9,19,20]$. Three adult intensive care trials, in predominantly medical patients, all 
Table 2 Patient demographics

\begin{tabular}{|c|c|c|c|}
\hline Demographic & $\begin{array}{l}\text { PICU-GRV } \\
N=42\end{array}$ & $\begin{array}{l}\text { PICU-noGRV } \\
N=45\end{array}$ & $P$ value \\
\hline \multicolumn{4}{|l|}{ Age (months) } \\
\hline median (IQR) & $5.3(1.9-44.5)$ & $9.7(1.5-78)$ & 0.724 \\
\hline Sex ( $\%$ male $)$ & $61.9 \%(26 / 42)$ & $57.7 \%(26 / 45)$ & 0.412 \\
\hline \multicolumn{4}{|l|}{ Admission weight $(\mathrm{kg})$} \\
\hline Median (IQR) & $5.4(3.8-15.5)$ & $9.8(4.09-26)$ & 0.220 \\
\hline $\mathrm{Z}$ score (weight for age) (mean SD) & $0.043(1.06)$ & $0.104(1.60)$ & 0.834 \\
\hline $\begin{array}{l}\text { Diagnostic group/PICU admission } \\
\text { reason }\end{array}$ & $\begin{array}{l}\text { Respiratory failure } 81 \% \\
\text { Neurological failure } \\
\quad 10 \% \\
\text { Sepsis } 4 \% \\
\text { Cardiovascular 2\% } \\
\text { Miscellaneous 3\% }\end{array}$ & $\begin{array}{l}\text { Respiratory failure } 42 \% \\
\text { Neurological failure } \\
\quad 42 \% \\
\text { Sepsis } 6.6 \% \\
\text { Cardiovascular } 4.4 \% \\
\text { Post-op surgical } 2.2 \% \\
\text { Trauma } 2.2 \% \\
\text { Miscellaneous } 0.6 \%\end{array}$ & \\
\hline \multicolumn{4}{|l|}{ PIM2 score } \\
\hline Mean (SD) & $0.05(0.079)$ & $0.09(.218)$ & $<0.001$ \\
\hline No IV sedation/opiate & $21 \%(9 / 42)$ & $0 \%$ & $<0.001$ \\
\hline IV Opiate \pm sedation & $50 \%(21 / 42)$ & $58 \% 26 / 46$ & \\
\hline Sedation + neuromuscular blockade & $29 \%(12 / 42)$ & $42 \%(19 / 45)$ & 0.263 \\
\hline $\begin{array}{l}\text { Died } \\
\text { LOV (days) }\end{array}$ & $2.3 \%(1 / 42)$ & $6.6 \%(3 / 45)$ & 0.339 \\
\hline $\begin{array}{l}\text { Median (IQR) } \\
\text { LOS (days) }\end{array}$ & $5(3-7)$ & $7.5(5.9-11.7)$ & $<0.001$ \\
\hline Median (IQR) & $6(3-9)$ & $13(11-20)$ & $<0.001$ \\
\hline
\end{tabular}

PICU Paediatric Intensive Care Unit, GRV gastric residual volume, IQR interquartile range, PIM2 a paediatric risk of mortality scoring tool, $S D$ standard deviation, $L O V$ length of mechanical ventilation, $L O S$ length of PICU stay

found that not measuring GRV was safe and improved the achievement of energy targets [24, 27, 29]. More specifically, in these trials, accepting a higher GRV (500 $\mathrm{ml}$ compared to $200 \mathrm{ml}$ ) [24] or not measuring GRV at all [25, 27, 29] did not adversely affect patient outcomes of ventilator-associated pneumonia (VAP) or gastrointestinal complications; however, it did improve the achievement of energy goals. A further study showed that just by measuring GRV, the risk of delivering inadequate energy increased by $38 \%$ [28].

Increasingly, this routine practice is being challenged in neonatal intensive care [10, 17, 26] PICUs [33] and across critical care generally $[4,9,15,18,30]$. The incidence of gastrointestinal complication of vomiting was higher in the routine GRV measured group. We speculate that in this unit, the frequent withholding of enteral feeds has led to attempts to compensate afterwards in order to reach daily nutritional goals. This could have led to an increased EN infusion rate or volume, with increased vomiting. We had no NEC in either group; however, NEC is a disease of neonates affecting preterm infants predominantly. As our cohort included few neonates, and pre-terms had been excluded, this was not surprising. The incidence of VAP (per 1000 ventilator days) was lower in PICU-noGRV (and non-significant) despite significantly higher PIM2 scores and longer length of ventilation that are risk factors for VAP in critically ill children [12]. The significantly higher severity of illness in PICU-noGRV might have been expected to negatively impact on energy delivery [5], but this was not the case. Despite a significantly longer time to initiate enteral feeding, once initiated, EN was tolerated well and was more consistently delivered in PICU-noGRV with sicker children.

In terms of the child's achievement of their predicted energy targets, we were not able to compare data beyond day four, as there were too few ventilated children in PICU-GRV. It may be that as length of PICU stay increases, the impact of this practice on energy delivery may become more apparent, but we do not know this. Delivery of adequate nutrition and energy requirements to critically ill children is vital, and we know that these children frequently receive suboptimal nutrition [23], with many of them already malnourished at PICU admission [8]; this further adversely impacting on their clinical outcomes [11]. PICU-noGRV had more consistent achievement of estimated energy goals, with PICU-GRV demonstrating both under and overfeeding according to their respective 
Table 3 Detailed enteral feeding data per PICU

\begin{tabular}{llll}
\hline EN parameter & PICU-GRV $n=42$ & PICU-noGRV $n=45$ & $P$ value \\
\hline Time to first feed (hours) mean and SD & $7.84(7.38)$ & $21.5(18.3)$ & $<0.001$ \\
Percentage of children continuously fed & $41 \%(17 / 41)$ & $100 \%(45 / 45)$ & $<0.001$ \\
Percentage of energy prescribed actually delivered & & & \\
Day 1 & $47.9(41.1)$ & $49.5(49.9)$ & 0.865 \\
Mean (SD) & $36.7(14-72)$ & $44.25(0-100)$ & 0.358 \\
Median (IQR) & & & 0.921 \\
Day 2 & $92.6(52.2)$ & $93.6(44.6)$ & 0.989 \\
Mean (SD) & $97(52.8-126.2)$ & $100(99.6-100.8)$ & 0.120 \\
Median (IQR) & & & 0.477 \\
Day 3 & $82.1(40.3)$ & $94.5(22.5)$ & 0.597 \\
Mean (SD) & $84.3(45-112.5)$ & $100(100-100.5)$ & 0.208 \\
Median (IQR) & & & \\
Day 4 & $101.2(39.2)$ & $96.2(16.9)$ & \\
Mean (SD) & $107(63.1-124.2)$ & $100(100-100.8)$ & \\
Median (IQR) & & & \\
Daily hours no EN delivered & $100 \%$ patients & $2 \%$ patients & \\
Day 1 & $8.4(5.3)$ & $6($ SD 0) & \\
Mean, (SD) & $100 \%$ patients & $0 \%$ patients & \\
Day 2 & $10.5(6.2)$ & $6.6 \%$ patients & \\
Mean (SD) & $100 \%$ patients & $14.3(\mathrm{SD} 4.4)$ & \\
Day 3 & $10.1(6.4)$ & & \\
Mean (SD) & $9.6(6.6)$ & patients & \\
Day 4 & & & \\
Mean (SD) & & & \\
\hline
\end{tabular}

$P I C U$ Paediatric Intensive Care Unit, GRV Gastric Residual Volume, EN enteral nutrition, SD standard deviation, $I Q R$ interquartile range local guidelines. On the one hand, GRV measurement in PICU-GRV seems to play a role in the higher incidence of underfeeding in this group. On the other hand, both units used predictive equations (Schofield equation) to set energy targets in ventilated children, as neither unit used indirect calorimetry $[21,31]$. Indirect calorimetry, although the gold standard to guide energy targets in the critically ill $[6,7]$, is available in very few PICUs (14\%) worldwide [14]. There are also accuracy imitations in the use of IC, mainly related to high-inspired oxygen requirements and air leaks, and predictive equations are considered acceptable in the absence of IC [21]. It is known that critically ill children need less energy than healthy children, and recommended dietary allowance (RDA) would provide too much energy in this setting. However, recent studies, comparing various equations, showed that Schofield equation, considered one of the most accurate, was less accurate in young infants, underestimating energy needs in the critically ill child [13]. As a consequence, PICU-noGRV local
Table 4 Adverse events data outcomes

\begin{tabular}{llll}
\hline Vomiting incidence in first 4 days & PICU-GRV $n=42$ & PICU-noGRV $n=45$ & $P$ value \\
\hline Day 1 $(n=42)$ & $7.1 \%(3 / 42)$ & $4.4 \%(2 / 45)$ & \\
Day 2 $(n=39)$ & $7.69 \%(3 / 39)$ & $2.2 \%(1 / 45)$ & \\
Day 3 $(n=31)$ & $3.2 \%(1 / 31)$ & $0 \%(0 / 45)$ & 0.39 \\
Day 4 $(n=20)$ & $0 \%(0 / 20)$ & $8.8 \%(4 / 45)$ & \\
Vomiting at any time (days 1-4) & & & 0.70 \\
Events during PICU admission & & 5.3 & \\
$\quad$ VAP per 1000 ventilator days & 7.1 & 0 & \\
Confirmed NEC & 0 & &
\end{tabular}

$P I C U$ Paediatric Intensive Care Unit, GRV gastric residual volume, VAP ventilator acquired pneumonia, NEC necrotizing enterocolitis 
guidelines set higher energy targets than the one estimated by Schofield equation in infants younger than 4 months, defined as the mean between energy amounts calculated with Schofield equation and RDA (Schofield equation + RDA / 2). In contrast, PICU-GRV local guidelines used Schofield equation to set energy targets in all age groups (Table 1). Consequently, the same intake of energy afforded to this young age group, considered accurate in PICU-noGRV, would be considered as overnutrition in PICU-GRV, according to their respective guidelines. Bronchiolitis was the primary diagnosis in infants younger than 4 months, and considering that fluid allowance is less restrictive in these children (as they require less intravenous drugs than other patients), these patients were more likely to receive nutrition above Schofield equation estimation, thus being defined as overfed in PICUGRV and normally fed in PICU-noGRV.

One of the main factors contributing to suboptimal energy delivery in the intensive care units is interruptions to enteral feeding $[3,16,22]$. In a recent survey of PICU nurses, elevated GRV was the main factor that led to feeds being withheld, but high GRVs have also been noted as a factor causing feed interruptions by others $[1,4,15,16,22]$. In our study, in the routine GRV measurement group, enteral feeds were withheld in all children for a median of $8 \mathrm{~h}$ in 24-h period, whereas in the no GRV group, enteral feeds were rarely withheld. Although interruptions may have occurred for other reasons (such as surgery or procedures) given the similarity in admitting diagnoses for both groups, this seems unlikely.

This pilot study has a number of limitations that need acknowledging. It was a pilot study (not informed by a power calculation), with small numbers, in only two European PICUs, and used both prospective and retrospective data collection which may have led to a patient selection bias. However, the retrospective data collection used a very detailed clinical information system with systematic record of nutritional intakes, vomiting and feeding intolerance symptoms. In addition, the incidence of NEC and VAP are very low overall, which make the results difficult to interpret. Despite our best efforts to ensure comparability of our patient populations and units, there may have been factors that affected our results. Our pragmatic definition of vomiting relied on nursereported data and may have been affected by other factors such as the child's diagnosis or sedation level, leading to coughing which may contribute to vomiting, and we did not collect data on sedation level. We did collect data on diarrhoea but could not use this due to the difficulty in quantifying this; however, this is not the main factor that clinicians are concerned about regarding not measuring GRV. In PICU-GRV, there were significant feed stoppage times, despite the median GRVs being less than the unit guideline threshold. We did not collect data on the reason for these feed stoppages, nor with compliance with unit guidelines; thus, there may be other reasons (in addition to GRV) that affected our results.
Furthermore, despite our best effort to ensure comparable PICUs, PICU-noGRV delivered continuous feeds over a 24-h period and PICU-GRV-administered bolus feeds more commonly; this may have impacted on the percentage of energy requirements delivered and on feeding tolerance. A further limitation is neither unit uses indirect calorimetry to estimate energy requirements, so energy requirements are based on predictive equations which may be inaccurate [32, 34]. Despite these limitations, we believe that most practices in the two units were similar except for the measurement of GRV: the earlier initiation of feeding in PICU-GRV and the use of continuous feeding in PICU-noGRV. Therefore, this pilot study provides some evidence that not measuring GRV does not increase adverse events or cause harm; however, the impact on energy delivery needs to be examined in a larger multicentre study.

\section{Conclusions}

Routine gastric residual volume measurement is common practice in PICUs internationally. Although we did not demonstrate that this practice significantly impaired the achievement of predicted energy targets in the first 4 days of a child's PICU admission, consistent achievement of energy targets was higher in PICU-noGRV. Most importantly, however, we found that not measuring GRV did not increase the incidence of vomiting, ventilator acquired pneumonia or necrotising enterocolitis. This is the key concern for clinicians at the bedside. The routine practice of GRV measurement remains important and needs to be questioned, and larger studies are needed in critically ill children to determine the impact on energy targets.

Acknowledgements The lead authors LT and FV are members of the Nurse Science (LT) and the Nutrition sections (FV, LT) of ESPNIC. This study was undertaken in collaboration by these members of the two sections.

Authors' Contributions LT developed the study idea and LT and FV designed the study protocol with input from LL. EA, ML, NG and LL undertook data collection for the study. SD undertook some preliminary data analysis.

Compliance with ethical standards All procedures performed in studies involving human participants were in accordance with the ethical standards of the institutional and/or national research committee and with the 1964 Helsinki Declaration and its later amendments or comparable ethical standards. In both studies, a waiver of consent was granted as no identifiable patient data was collected.

Conflict of interest The authors declare that they have no conflicts of interest.

Open Access This article is distributed under the terms of the Creative Commons Attribution 4.0 International License (http:// creativecommons.org/licenses/by/4.0/), which permits unrestricted use, distribution, and reproduction in any medium, provided you give 
appropriate credit to the original author(s) and the source, provide a link to the Creative Commons license, and indicate if changes were made.

\section{References}

1. Ahmad S, Kaitha S, Morton J, Ali T (2012) Nasogastric tube feedings and gastric residual volume: a regional survey. Southern Med J 105:394-398

2. Bartlett-Ellis R, Fuehne $J$ (2015) Examination of accuracy in the assessment of gastric residual volume: a simulated, controlled study. JPEN J Parenter Enteral Nutr 39:434-440 231

3. Bockenkamp B, Jouvet P, Arsenault V, Beausejour M, Pelletier V (2009) Assessment of calories prescribed and delivered in critically ill children. Clin Nutr ESPEN 4:e172-e175

4. Bollineni D, Minocha A (2011) Nursing practice of checking gastric residual volumes based on old dogmas: opportunity to improve patient care while decreasing healthcare costs. J La State Med Soc 163:205-267

5. Briassoulis G, Zavras N, Hatzis T (2001) Effectiveness and safety of a protocol for promotion of early intragastric feeding in critically ill children. Pediatr Crit Care Med 2:113-121

6. Briassoulis G, Briassouli E, Tavladaki T, Ilia S, Fitrolaki DM, Spanaki AM (2014) Unpredictable combination of metabolic and feeding patterns in malnourished critically ill children: the malnutrition-energy assessment question. Intensive Care Med 40:120-122

7. Briassoulis G, Ilia S, Meyer R (2016) Enteral nutrition in PICUs: missing not impossible! Ped Crit Care Med 17:85-87

8. Costa C, Tonial C, Garcia P (2016) Association between nutritional status and outcomes in critically-ill pediatric patients - a systematic review. J Pediatr:223-229

9. Elke G, Felbinger T, Heyland D (2015) Gastric residual volume in critically ill patients: a dead marker or still alive? Nutr Clin Practi 30:59-71

10. Gregory K, Connolly T (2012) Enteral feeding practices in the NICU. Adv Neonatal Care 12:46-55

11. Grippa R, Silva P, Barbosa E, Bresolin N, Mehta N, Moreno Y (2017) Nutritional status as a predictor of duration of mechanical ventilation in critically ill children. Nutr J 33:91-95

12. Gupta S, Boville B, Blanton R, Lukasiewicz G, Wincek J, Bai C, Forbes M (2015) A multicentred prospective analysis of diagnosis, risk factors, and outcomes associated with pediatric ventilatorassociated pneumonia. Pediatr Crit Care Med 16:e65-e73 273

13. Jotterand-Chaparro C, Taffe P, Moullet C, Depeyre J, Longchamps D, Perez M, Cotting J (2017) Performance of predictive equations specifically developed to estimate resting energy expenditure in ventilated critically ill children. J Pediatr. https://doi.org/10.1016/j. jpeds.2016.12.063 284

14. Kerklaan D, Fivez T, Mehta N, Messoten D, van Rosmalen J, Hulst J, Van den Berghe G, Joosten K, Verbruggen S (2016) Worldwide Survey of Nutritional Practices in PICUs. Pediatr Crit Care Med 17:1-18

15. Kuppinger D, Rittler P, Hartl W, Ruttinger D (2013) Use of gastric residual volume to guide enteral nutrition in critically ill patients: a brief systematic review of clinical studies. Nutr J:1075-1079

16. Leong A, Cartwright K, Guerra C, Joffe A, Mazurak V, Larsen B (2013) A Canadian survey of perceived barriers to initiation and continuation of enteral feeding in PICUs. Pediatr Crit Care Med 15:2

17. Li YL, Lin HC, Mugas Torrazza R, Parker L, Talaga E, Neu J (2014) Gastric residual evaluation in preterm neonates: a useful monitoring technique or a hindrance? Pediatr Neonatol 55:335-340

18. Martinez E, Pereira L, Gura K, Stenquist N, Ariagno K, Nurko S, Mehta N (2017) Gastric emptying in critically ill children. JPEN J Parenter Enteral Nutr. https://doi.org/10.1177/0148607116686330
19. McClave S, Snider H (2002) Clinical use of gastric residual volumes as a monitor for patients on enteral tube feeding. JPEN J Parenter Enteral Nutr 26:S43-S50

20. McClave S, Lukan J, Steafater C, Lowen C, Looney S, Matheson P, Gleeson K, Spain D (2005) Poor validity of residual volumes as a marker for risk of aspiration in critically ill patients. Crit Care Med 33:324-330

21. Mehta N, Compher C (2009) A.S.P.E.N. Clinical guidelines: nutrition support of the critically ill child. J JPEN J Parenter Enteral Nutr 33:260-276

22. Mehta N, McAleer D, Hamilton S, Naples E, Leavitt K, Mitchell P, Duggan C (2010) Challenges to optimal enteral nutrition in a multidisciplinary pediatric intensive care unit. JPEN J Parenter Enteral Nutr 34:38-45

23. Mehta N, Bechard L, Cahill N, Wang M, Day A, Duggan C, Heyland D (2012) Nutritional practices and their relationship to clinical outcomes in critically ill children - an international multicentre cohort study. Crit Care Med 40:2204-2211 222

24. Montejo J, Minambres E, Bordeje L, Mesejo A, Acosta J, Heras A, Ferre M, Fernandez-Ortega F, Vaquerizo C, Manzandeo R (2010) Gastric residual volume during enteral nutrition in ICU patients: the REGANE study. Intensive Care Med 36:1386-1393

25. Ozen N, Tosun N, Yamanel L, Altintas N, Kilciler G, Ozen V (2016) Evaluation of the effect on patient parameters of not monitoring gastric residual volume in intensive care patients on a mechanical ventilator receiving enteral nutrition: a randomized clinical trial. J Crit Care 33:137-144 255

26. Parker L, Torrazza RM, Yuefeng L, Talaga E, Shuster J, Neu J (2015) Aspiration and evaluation of gastric residuals in the NICU: state of the science. J Perinat Neonatal Nurs 29:51-59

27. Poulard F, Dimet J, Martin-Lefevre L, Bontemops F, Fiancette M, Clementi E, Lebert C, Renard B, Reignier J (2010) Impact of not measuring residual gastric volume in mechanically ventilated patients receiving early enteral feeding: a prospective before-after study. JPEN J Parenter Enteral Nutr 34:125-130 252

28. Quenot JP, Plantefeve G, Baudel JL, Camilatto I, Bertholet E, Cailliod R, Reignier J, Rigaud JP (2010) Bedside adherence to clinical practice guidelines for enteral nutrition in critically ill patients receiving mechanical ventilation: a prospective, multicentre, observational study. Criti Care 14:R37

29. Reignier J, Mercier E, Le Gouge A, Boulain T, Desachy A, Bellec F, Clavel M, Frat JP, Quenot JP (2013) Lascarrou JB; for the clinical research in intensive care and sepsis (CRICS) group effect of not monitoring residual gastric volume on risk of ventilator-associated pneumonia in adults receiving mechanical ventilation and early enteral feeding. JAMA 309(3):249-256. https://doi.org/10.1001/ jama.2012.196377

30. Ridley E, Davies A (2011) Practicalities of nutrition support in the intensive care unit: the usefulness of gastric residual volume and Prokinetic agents with enteral nutrition. Nutr J:1-4

31. Schofield W (1985) Predicting basal metabolic rate, new standards and review of previous work. Hum Nutr Clin Nutr 39:5-41

32. Tavladaki T, Spanaki AM, Dimitriou H, Briassoulis G (2017) Alterations in metabolic patterns in critically ill patients - is there need of action? Eur J Clin Nutr:431-433

33. Tume L, Carter B, Latten L (2013) A UK and Irish survey of enteral nutrition practices in paediatric intensive care units. Br J Nutr 109: 1304-1322 224

34. Tume LN, Latten L, Kenworthy L (2017) Paediatric intensive care nurses' decision-making around gastric residual volume measurement. Nurs Crit Care. https://doi.org/10.1111/nicc.12304

35. Valla F, Gaillard-Le Roux B, Ford-Chessel C et al (2016) NutriReaPed 2014: the Nursing survey on nutrition practices in Frenchspeaking pediatric intensive care units. JPGN J Parenter Enteral Nutr 62;2: 174-179. 226 doi:https://doi.org/10.1097/MPG. 000000000000930227 